\title{
KOMUNITAS BURUNG DI PULAU TIDUNG KECIL KEPULAUAN SERIBU
}

\author{
Paskal Sukandar $^{1^{*}}$, Ai Winarsih ${ }^{2}$, Fahma Wijayanti ${ }^{2}$ \\ ${ }^{I}$ Program Studi Biologi Fakultas MIPA Universitas Negeri Jakarta \\ ${ }^{2}$ Program Studi Biologi Fakultas Sains dan Teknologi UIN Syarif Hidayatullah Jakarta \\ *Corresponding author:paskal_sukandar@yahoo.com
}

\begin{abstract}
Tidung Kecil Island had potential as bird's habitat because the condition of forest better than Tidung Besar. Bird's habitat in Tidung Kecil Island also had bad potential because of logging and burned in vegetation areal for build and for activity of tourism. Study about bird were very important because we could know the change that happened in one ecosystem. The purposed of this research was to know the variety of bird and usefully of vegetation as bird's habitat in Tidung Kecil Island. This researched hold on January until March 2015 in Tidung Kecil Island, Thousand Island, Jakarta. This research carried out by combination of IPA (Index Point Of Abundance) method and transect method that divided into 9 point along transect. The result of researched were 29 species of bird from 19 family with IPA method and 31 species of bird from 20 family with Mackinnon list method. Composition of bird species include of 24 resident bird species and 7 migrant bird species. The number of variety species index was 2,39 (medium). Evenness index value was 0,7 (high). The number of species richness was 4,31(high). The species of tree that often used by bird was Casuarina equisetifolia (76,47\%). The most used base of vertical level tree by bird in Tidung Kecil Island was level three. Conservation status in Tidung Kecil Island based on IUCN (International Union for Conservation of Nature and Natural Resources) were 100\% (least concern). Based on Government Regulations No.7 year 1999, there were 7 species of bird that were protected. There were no species of bird that were protected by CITES (Convention on International Trade of Endangered Spesies of Wild Fauna and Flora).
\end{abstract}

$\underline{\text { Keywords : Bird community, variety, vegetation, conservation status }}$

\section{PENDAHULUAN}

Kepulauan Seribu terdiri dari banyak pulau, salah satunya adalah Pulau Tidung. Secara administratif Pulau Tidung termasuk kedalam wilayah Kabupaten Kepulauan Seribu, DKI Jakarta. Pulau Tidung terbagi atas dua gugusan pulau yaitu Pulau Tidung Besar dan Pulau Tidung Kecil. Sebagai salah satu pulau yang terdapat pada gugusan Kepulauan Seribu, Pulau Tidung Kecil potensial sebagai habitat bagi burung karena kondisi hutan lebih baik dan tingkat pembangunan masih rendah dibandingkan dengan Pulau Tidung Besar (Pemprov DKI, 2010). Pulau-pulau di Kepulauan Seribu termasuk Pulau Tidung Kecil umumnya dihuni oleh berbagai jenis burung terutama jenis-jenis burung air dan burung pantai. Menurut Mardiastuti (1992), sebanyak 15 jenis burung air ditemukan di Pulau Rambut dan populasi terbesar didominasi oleh famili Heron (Ardeidae) dan Cormorant (Phalacrocoracidae), dimana Pulau Rambut merupakan salah satu pulau yang terdapat di Kepulauan Seribu. Kepulauan Seribu merupakan kumpulan pulau yang menunjang keberlangsungan hidup suatu burung. Umumnya habitat di Kepulauan Seribu digunakan oleh burung sebagai tempat beristirahat, bersarang, tempat berkembang biak, dan tempat berlindung dari ancaman predator. Habitat burung di Pulau Rambut terdiri dari hutan mangrove primer, hutan mangrove sekunder dan hutan dataran kering campuran (Mardiastuti, 1992).

Sebagai salah satu komponen penting ekosistem, burung mempunyai hubungan timbal balik dan saling tergantung dengan lingkungannya. Dengan demikian, burung dapat dimanfaatkan langsung atau tidak langsung sebagai bioindikator lingkungan 
(Hernowo \& Prasetyo, 1989). Namun, keberadaan habitat burung di Pulau Tidung Kecil berpotensi mengalami gangguan akibat penebangan dan pembakaran kawasan bervegetasi untuk tujuan pembangunan (Andam, 2012) dan aktifitas kunjungan wisatawan. Akibatnya, areal-areal bervegetasi yang merupakan habitat burung yang paling penting, semakin berkurang sehingga dikhawatirkan banyak jenis burung yang akan kehilangan habitatnya. Perlu dilakukan penelitian untuk memperoleh informasi mengenai keanekaragaman jenis burung burung serta pemanfaatan vegetasi oleh burung dalam upaya pengelolaan dan pemanfaatan lahan di kawasan tersebut, agar kelestarian burung dan fungsi ekosistem di kawasan tersebut dapat dipertahankan.

Tujuan dari penelitian ini adalah mengetahui keanekaragaman jenis burung yang ada di Pulau Tidung Kecil dan mengetahui pemanfaatan vegetasi sebagai habitat burung di Pulau Tidung Kecil

\section{MATERIAL DAN METODE}

Lokasi penelitian dilakukan di Pulau Tidung Kecil, Kelurahan Pulau Tidung, Kecamatan Kepulauan Seribu Selatan, Kabupaten Kepulauan Seribu, Jakarta. Penelitian dimulai pada bulan Januari hingga bulan Maret 2015. Pengamatan dilakukan pada waktu pagi hari pukul 06.00-09.30 WIB dan sore haripukul 16.00-18.00 WIB dengan asumsi burung mulai aktif melakukan aktifitas pada rentang waktu ini.

Survei pendahuluan dilakukan terlebih dahulu untuk mengenal lokasi atau habitat yang akan menjadi tempat pengamatan, kemudian untuk penelusuran jalur dan penentuan titik pengamatan, dan mengenal jenisjenis burung yang umum dijumpai di titik pengamatan. Pengumpulan data burung dilakukan dengan metode kombinasi antara metode IPA (Index Point of Abundance) dan dengan metode jalur (transect) (Bibby et al., 2000). Metode ini adalah metode yang dilakukan dengan mengikuti jalur yang telah ada dan berhenti di setiap jarak tertentu Metode ini dilakukan dengan berjalan sepanjang jalur dari ujung barat hingga ke ujung timur Pulau Tidung Kecil. Dibuat 9 titik pengamatan di sepanjang transek, kemudian titik-titik tersebut dibagi dua jalur pengamatan, jalur 1 meliputi bagian barat hingga tengah pulau sebanyak 4 titik, sedangkan jalur 2 meliputi pesisir bagian tengah hingga bagian ujung timur sebanyak 5 titik. Setiap titik dilakukan pengamatan selama 10 menit dengan jarak pengamatan ke kiri dan kanan sejauh $25 \mathrm{~m}$ dan jarak antar titik sejauh 100 $\mathrm{m}$, agar tidak terjadi pengulangan pencatatan.

Data penelitian yang dikumpulkan diantaranya jumlah jenis burung, jumlah individu burung pada lokasi pengamatan, waktu penjumpaan terhadap jenis burung, dan titik kordinat pengamatan. Data yang diperoleh kemudian dikumpulkan untuk dianalisis lebih lanjut. Untuk mengetahui kekayaan jenis burung digunakan metode daftar jenis MacKinnon atau yang dikenal juga dengan metode daftar 20 jenis MacKinnon (Tweenty Species List). Menurut MacKinnon (1990) setiap daftar berisi dua puluhjenis burung, jenis berikutnya meskipun sama dapat dicatat lagi pada daftar yangbaru. Metode ini dapat digunakan untuk menduga kekayaan jenis burung secarakualitatif di suatu tipe habitat. Dalam penelitian ini dibuat sebanyak sepuluh jenisdalam setiap daftar (Sutopo, 2008).

Penyebaran jenis burung menurut struktur vegetasi, dilakukanpenggambaran strata vegetasi yang ada disetiap tipe habitat yang diteliti. Pemanfaatan ruang vegetasi oleh burung secara umum terbagi menjadi dua strata,yaitu tumbuhan bawah dan tumbuhan penutup (Utari, 2000). Rahayuningsih et al., (2007) membagi menjadi 4 strata vegetasi pohon. Pemanfaatan ruang vegetasi oleh burung secara umum dibagi menjadi bagian tajuk dan bagian batang (Gambar 3). Pembagian tajuk dibagi lagi menjadi bagian tajuk atas, tajuk tengah dan tajuk bawah. Batasan bagian tajuk bagian atas adalah 1/3 bagian atas dari tinggi total tajuk, kemudian bagian bawah adalah $1 / 3$ tinggi total tajuk bagian bawah, dan bagian tengah adalah 1/3 tinggi total tajuk bagian tengah. Untuk pemanfaatan bagian batang dari bagian tajuk bawah hingga berbatasan dengan lantai hutan, sedangkan 
lantai hutan adalah vegetasi bawah (Kaban, 2013).

Nilai keanekaragaman jenis burung pada tiga lokasi penelitian dihitung dengan menggunakan indeks Shannon-Wienner

$\mathrm{H}^{\prime}=\sum \ln \mathrm{Pi}$

$\mathrm{H}^{\prime}=$ Nilai indeks Shannon, $\mathrm{Pi}=\mathrm{ni} / \mathrm{N}, \mathrm{Ni}=\mathrm{Jum}-$ lah individu jenis ke-i; $\mathrm{N}=$ Total jumlah individu; $S=$ Total jumlah jenis; $\ln =$ Logaritma natural.

Nilai keanekaragaman jenis $<1,5$ dikategorikan rendah, selanjutnya nilai $1,5 \mathrm{~s} / \mathrm{d} \mathrm{3,5}$ dikategorikan sedang dan nilai $>3,5$ menunjukkan keanekaragamanyang tinggi (Magurran, 1988).

Indeks Kemerataan dapat dihitung dengan persamaan sebagai berikut:

$\mathbf{E}=\frac{\mathbf{H}^{\prime}}{\ln \mathrm{S}}$

$\mathrm{E}=$ Indeks kemerataan; $\mathrm{H}^{\prime}=$ Indeks keanekaragaman Shannon; S=Jumlah jenis; $\ln =$ Logaritma natural; Bila $\mathrm{E}$ mendekati 0 (nol), jenis penyusun tidak banyak ragamnya, ada dominasi dari jenis tertentu dan menunjukkan adanya tekanan terhadap ekosistem. Bila E mendekati 1 (satu), jumlah individu yang dimiliki antar jenis tidak jauh berbeda, tidak ada dominasi dan tidak ada tekanan terhadap ekosistem (Ludwig \&Reynolds 1988).

Nilai indeks kekayaan jenis dapat dihitung dengan persamaan sebagai berikut:

$$
\mathbf{R}=\frac{(\mathbf{S}-\mathbf{1})}{\ln \mathbf{N}}
$$

$\mathrm{R}=$ Indeks Kekayaan Jenis Margalef; $\mathrm{S}=$ Jumlah Jenis; N=Jumlah Individu; ln=Logaritma natural; Nilai Indeks kekayaan jenis $>4,0$ dikategorikan baik, selanjutnya nilai 2,5 hingga 4,0 dikategorikan moderat dan nilai $<2,5$ menunjukkan keanekaragaman yang buruk (Jorgensen et al.. 2005).

Setiap jenis tumbuhan digunakan oleh burung sebagaitempat untuk melakukan berbagai aktifitas, seperti mencari makan (Feeding), membersihkan bulu dan bertengger (Resting), bergerak dan sosial (Social)maupun bersarang (Nest). Penggunaan vegetasi oleh burung dihitung dengan menggunakan rumus:

$$
\mathrm{Ft}=\frac{\mathrm{St}}{\mathrm{Sp}} \times 100 \%
$$

$\mathrm{Ft}=$ Fungsi suatu jenis vegetasi bagi burung, $\mathrm{St}=$ Banyaknya jenis burung yang menggunakan suatu jenis vegetasi pada plot pengamatan, $\mathrm{Sp}=$ Seluruh jenis burung pada plot pengamatan yang terdapat suatu jenis vegetasi tersebut

\section{HASIL DAN PEMBAHASAN Kondisi Habitat}

Gambaran kondisi habitat di lokasi penelitian meliputi kodisi fisik dan vegetasi. Kondisi fisik di lokasi pengamatan dilihat dari cuaca, kecepatan angin, kelembaban dan temperatur. Sedangkan habitat burung di Pulau Tidung Kecil dilihat dari tipe vegetasi yaitu tergolong ke dalam hutan sekunder campuran. Secara umum jenis-jenis vegetasi pada jalur hutan sekunder campuran yang teramati adalah pohon kelapa (Cocos nucifera), kedondong kambing (Spondiassp.), pohon ketapang (Terminalia cattapa), pohon sukun (Artocarpus communis), cemara laut (Casuarina equisetifolia), waru laut (Thespesia populnea) dan pandan laut (Pandanus tectorius). Vegetasi tampak kering dan pada beberapa bagianvegetasi berwarna cokelat. Berdasarkan hasil pengamatan, terdapat dua jenis tegakan yang dominanyaitu pohon kelapa (Cocos nucifera) sebanyak 43,50\% dan pohon kedondong kambing (Spondias sp.) sebanyak 18,08\%. Pohon kelapa merupakan salah satutanaman yang dibudidayakan di Pulau Tidung Kecil karena tanaman kelapa merupakan tanaman yang dapat hidup dengan baik di pesisir pantai. Penyebaran pohon kedondong kambing ditemukan hampir di seluruh kawasan Pulau TidungKecil.

\section{Komposisi dan Kekayaan Jenis Burung}

Jumlah jenis burung yang didapatkan dengan menggunakan metode IPA adalah 29 jenis burung dari 19 famili, sedangkan dengan menggunakan metode daftar jenis Mackinnon didapatkan 31 jenis burung dari 20 famili. Total daftar jenis yang didapatkan dengan metode kekayaan jenis Mackinnon adalah sebanyak 23 daftar jenis. 
Berdasarkan jumlah individu, nilai persentase tertinggi adalah bondol peking (Lonchura punctulata) sebesar 37,63\%. Selain itu, terdapat empat jenis yang menempati persentase terendah $(0,15 \%)$ yaitu kareo padi (Amaurornis phoenicurus), gajahan pengala (Numenius phaeopus), cerek tilil (Charadrius alexandrinus) dan bubut pacar jambul (Clamator coromandus). Persentase jumlah individu setiap jenis burung dapat dilihat pada Tabel 1.

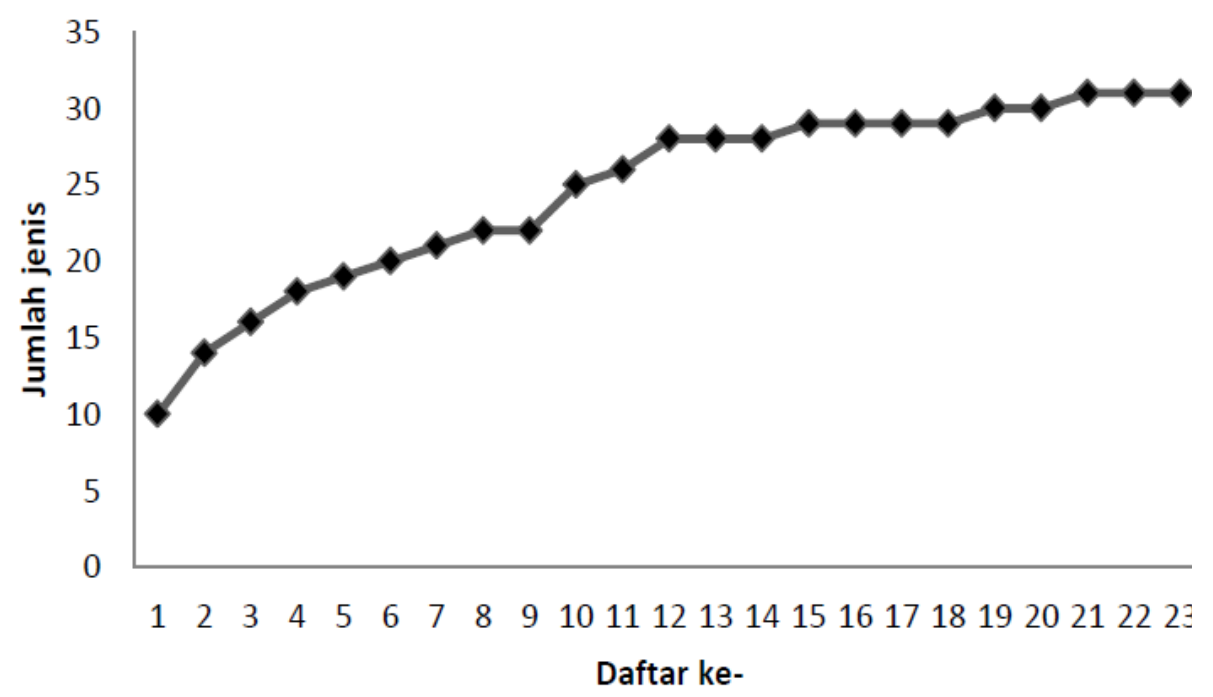

Gambar 1. Daftar kekayaan jenis burung berdasarkan daftar jenis MacKinnon

\section{Keanekaragaman Jenis Burung}

Nilai indeks keanekaragaman jenis burung yang ditemukan di Pulau Tidung Kecil, Kepulauan Seribu adalah sebesar 2,39. Nilai keanekargaman jenis burung (H') di Pulau Tidung Kecil, Kepualauan Seribu masuk ke dalam ketegori sedang (medium). Nilai tersebut menunjukkan ekosistem di tempat tersebut cukup memadai dalam memberi daya dukung terhadap kehidupan burung. Hal ini dapat terlihat dengan ditemukannya berbagai komunitas burung seperti kelompok burung pantai, burung air dan juga burung teresterial yang menempati Pulau Tidung Kecil.Nilai medium untuk indeks keanekaragaman menunjukkan bahwa terdapat sebuah keseimbangan di ekosistem di Pulau Tidung Kecil. Hal ini sejalan dengan pernyataan Kurnia et al., (2005) bahwa keanekaragaman berhubungan dengan banyaknya jenis dan jumlah individu tiap jenis sebagai penyusun komunitas. Keanekaragaman juga berhubungan dengan keseimbangan jenis dalam komunitas artinya apabila nilai keanekaragaman tinggi, maka keseimbangan dalam komunitas tersebut juga tinggi, begitu juga sebaliknya Habitat yang berane- karagam dapat mempengaruhi sumber pakan bagi burung. Hal ini didukung oleh pernyataan Kapisa (2011) bahwa nilai keanekaragaman jenis dapat mengindikasikan daya dukung suatu habitat terhadap kehidupan burung. Semakin tinggi nilai keanekaragaman menunjukkan kondisi habitat yang baik dalam mendukung kehidupan burung secara alami. Pernyataan ini juga didukung oleh Mulyani \& Pakpahan (1993) bahwa nilai keanekaragaman jenis burung dipengaruhi oleh beberapa faktor, seperti luas wilayah, keanekaragman habitat dan kualitas lingkungan secara umum. Suatu komunitas disusun oleh banyak jenis dengan kelimpahan yang relatif sama, makakeanekaragaman jenisnya akan tinggi (van Helvort, 1981).

Kemerataan jenis burung dalam suatu habitat dapat ditandai dengan tidak adanya jenis-jenis yang dominan. Apabila setiap jenis memiliki jumlah individu yang sama, maka kemerataan jenis pada komunitas tersebut memiliki nilai maksimum, tetapi apabila jumlah individu pada masing-masing jenis berbeda jauh maka menyebabkan kemerataan jenis memiliki nilai minimum (Santosa, 1995). 
Tabel 1. Presentase individu tiap jenis burung

\begin{tabular}{|c|c|c|c|c|}
\hline No & Famili & Nama Lokal & Nama Ilmiah & $\begin{array}{c}\text { Persentase } \\
(\%)\end{array}$ \\
\hline \multirow{3}{*}{1} & \multirow{3}{*}{ Ardeidae } & Cangak abu & Ardea cinerea & 0.46 \\
\hline & & Kokokan laut & Butorides striatus & 1.67 \\
\hline & & Kuntul karang & Egretta sacra & 0.30 \\
\hline 2 & Rallidae & Kareo padi & Amaurornis phoenicurus & 0.15 \\
\hline \multirow{2}{*}{3} & \multirow{2}{*}{ Charadriidae } & Cerek kernyut* & Pluvialis fulva & 10.02 \\
\hline & & Cerek tilil* & Charadrius alexandrinus & 0.15 \\
\hline \multirow{2}{*}{4} & \multirow{2}{*}{ Scolopacidae } & Gajahan pengala* & Numenius phaeopus & 0.15 \\
\hline & & Trinil pantai* & Acitis hypoleucos & 0.30 \\
\hline 5 & Columbidae & Tekukur biasa & Streptopelia chinensis & 4.25 \\
\hline \multirow{3}{*}{6} & \multirow{3}{*}{ Cuculidae } & Bubut Pacar jambul & Clamator coromandus & 0.15 \\
\hline & & Kangkok besar* & Cuculus sparverioides & 0.61 \\
\hline & & Bubut alang-alang & Centropus bengalensis & 0.30 \\
\hline 7 & Apodidae & Walet sarang putih & Callocalia fuciphaga & 2.43 \\
\hline 8 & Alcedinidae & Cekakak sungai & Halcyon chloris & 6.22 \\
\hline \multirow{2}{*}{9} & \multirow{2}{*}{ Hirundinidae } & Layang-layang api* & Hirundo rustica & 1.82 \\
\hline & & Layang-layang batu & Hirundo tahitica & 2.88 \\
\hline \multirow{2}{*}{10} & \multirow{2}{*}{ Pycnonotidae } & Cucak kutilang & Pycnonotus aurigaster & 5.16 \\
\hline & & Merbah cerukcuk & Pycnonotus goiavier & 2.28 \\
\hline 11 & Oriolidae & Kepodang kuduk hitam & Oriolus chinensis & 0.76 \\
\hline 12 & Corvidae & Gagak hutan & Corvus enca & 2.58 \\
\hline 13 & Acanthizidae & Remetuk laut & Gerygone sulphurea & 3.64 \\
\hline 14 & Rhipiduridae & Kipasan belang & Rhipidura javanica & 0.46 \\
\hline 15 & Pachycephalidae & Kancilan bakau & Pachycephala grisola & 0.46 \\
\hline 16 & Artamidae & Kekep babi & Artamus leucorynchus & 5.61 \\
\hline \multirow{2}{*}{17} & \multirow{2}{*}{ Nectarinidae } & Burung madu kelapa & Antrhreptes malacensis & 6.83 \\
\hline & & Burung madu sriganti & Cinnyris jugularis & 1.82 \\
\hline 18 & Passeridae & Burung gereja erasia & Passer montanus & 0.46 \\
\hline \multirow{2}{*}{19} & \multirow{2}{*}{ Estrildidae } & Bondol peking & Lonchura punctulata & 37.63 \\
\hline & & Bondol haji & Lonchura maja & 0.46 \\
\hline
\end{tabular}

Keterangan : (*)Burung migran

Nilai kemerataan (E) jenis burung yang didapatkan di Pulau Tidung Kecil sebesar 0,7. Nilai kemerataan tersebut mendekati angka 1 yang menunjukan bahwa kemerataan tinggi. Hal ini didukung oleh pernyataan Odum (1993), nilai indeks kemerataan dapat dikatakan tinggi jika >0,60. Meskipun bondol peking merupakan jenis dengan populasi yang dominan, namun nilai kemerataan jenis burung di Pulau Tidung Kecil yang tinggi menunjukkan bahwa populasi jenis burung di Pulau Tidung Kecil tergolong merata.

Nilai kekayaan jenis burung di Pulau Tidung Kecil, Kepulauan Seribu adalah sebesar 4,31. Nilai kekayaan jenis burung di
Pulau Tidung Kecil termasuk kedalam kriteria baik yaitu nilai berkisar $>4,0$ (Jorgensen et al., 2015). Hal tersebut menunjukkan banyaknya jenis yang ditemukan. Semakin baik nilai kekayaan jenis burung menunjukkan tingkat keragaman habitat yang ada di Pulau Tidung Kecil. Nilai kekayaan yang tinggi menan-dakan terdapat habitat yang beragam di suatu lokasi. Semakin beranekaragam struktur habi-tat (keanekaragaman jenis tumbuhan dan struktur vegetasi) maka akan semakin besar keanekaragaman jenis satwa yang menempati suatu ekosistem. 


\section{Penggunaan Vegetasi Oleh Burung}

Tegakan pohon di Pulau Tidung Kecil terdiri dari berbagai jenis tegakan. Tipe tegakan pohon di Pulau Tidung Kecil termasuk pada tipe tegakan campuran. Vegetasi yang mengisi Pulau Tidung Kecil yaitu vegetasi perkebunan, vegetasi padang ilalang dan vegetasi hutan sekunder campuran. Lahan perkebunan terdapat di bagian Barat Pulau Tidung Kecil yang didominasi oleh tumbuhan sekunder seperti pohon sukun (Artocarpus communis), pohon jambu air (Eugenia aquea) dan pohon kelapa (Cocos nucifera). Tanaman perkebunan tersebut ditanam dan dikelola oleh Kemen-trian Pertanian. Vegetasi ilalang terdapat di bagian tengah hingga timur Pulau Tidung Kecil. Vegetasi hutan berada dibagian timur Pulau Tidung Kecil yang diisi beberapa tegakan yang merupakan tegakan campuran seperti cemara laut (Casuarina equisetifolia), waru laut (Thespesia populnea), pandanlaut (Pandanus tectorius) dan rogo-rogo (Premna serratifolia).

Habitat burung yang tersedia di Pulau Tidung Kecil diindikasikan sebagai habitat yang baik. Hal ini ditunjukkan dengan masih dijumpainya beberapa jenis burung yang termasuk indikator baiknya sebuah ekosistem seperti Halcyon chloris yang berasal dari famili Alcedinidae. Suku Alcedinidae memiliki ketergantungan yang besar dengan kawasan perairan sebagai lokasi bersarang (nesting sites), lokasi mencari pakan (feeding sites), dan lokasi istirahat (resting sites) (Swastikaningrum et al., 2012). Hal ini didukung oleh pernyataan Idaman (2007) bahwa Alcedo coerulescens yang berasal dari famili Alcedinidae merupakan jenis burung yang dapat dijadikan sebagai indikator lingkungan yang baik. Pernyataan tersebut juga serupa dengan Bibby et al., (2008) bahwa burung dapat menjadi indikator yang baik bagi keanekaragaman hayati dan perubahan. Variasi habitat turut mendukung kekayaan jenis burung di Pulau Tidung Kecil. Menurut Howes et al., (2003), kehadiran suatu jenis burung tertentu, pada umumnya disesuaikan dengan kesukaannya terhadap habitat tertentu. Oleh karena itu variasi habitat akan memberi relung yang lebih banyak untuk dapat ditempati berbagai jenis burung sehingga burung yang ditemukan lebih bervariasi.

Pengumpulan data burung dilakukan selama 3 hari. Cuaca saat dilakukan pengamatan sangat cerah pada hari pertama sehingga pengamatan tidak terhambat namun cuaca pada hari kedua mendung dan sedikit hujan dan kembali cerah pada pengamatan hari terakhir. Cuaca saat dilakukan pengamatan tergolong baik. Hal ini disebabkan musim hujan tertinggi adalah bulan Januari sedangkan penelitian dilakukan pada bulan Februari. Nilai rata-rata suhu sebesar $28,43^{\circ} \mathrm{C}$, kelembaban $76,2 \%$ dan kecepatan angin sebesar 2,23 knot. Menurut Krebs (2013) aktifitas burung dipengaruhi oleh faktor waktu yaitu pagi hari yang suhunya lebih rendah daripada siang hari, lebih banyak melakukan aktifitas. Hal ini merupakan efek setelah lama melakukan istirahat pada malam hari. Sedangkan sore hari merupakan aktifitas dalam mengumpulkan sejumlah energi untuk persiapan menjelang istirahat. Kondisi seperti ini cukup ideal untuk dilakukannya pengamatan karena burung mulai aktif beraktifitas saat pagi hari dan sore hari dengan kondisi fisik yang normal.

Burung penetap seperti bondol peking (Lonchura punctulata) merupakan jenis yang paling banyak ditemui saat pengamatan. Hal ini dikarenakan terdapat habitat yang menunjang kehidupan bondol peking. Habitat yang disukai burung ini adalah semak dan padang ilalang. Bondol peking merupakan burung pemakan biji, sehingga vegetasi semak dan padang ilalang merupakan vegetasi yang memenuhi kebutuhan pakannya. Selain itu bondol peking juga memiliki kebiasaan hidup berpasangan atau dalam kelompok kecil, segera bergabung dengan kelompok bondol lainnya. Oleh sebab itu burung ini sering ditemukan dalam jumlah banyak. Burung penetap dengan jumlah individu paling sedikit adalah kareo padi Amaurornis phoenicurus) dan bubut pacar jambul (Clamator coromandus) yaitu sebanyak $0,15 \%$. Kedua jenis burung tersebut sangat sensitif terhadap keberadaan manusia, sehingga jarang sekali terlihat. Selain itu kedua jenis burung tersebut menyukai habitat semak yang sulit ditemukan 
langsung dan lebih sering diidentifikasi melalui suara. Hal ini didukung oleh pernyataan Mackinnon et al., (2010) bahwa bubut alang-alang memilih belukar, payau, dan daerah berumput terbuka termasuk padang alang-alang. Kareo padi umumnya hidup sendirian, kadang-kadang berdua atau bertiga, mengendap-endap dalam semak yang lembab dan tinggal di tempat yang cukup rapat untuk bersembunyi. Selain burung penetap, ditemukan juga jenis burung-burung migran. Burung migran dapat menempati habitat yang dianggap cukup memadai kehidupannya. Ditemukannya burung migran di Pulau Tidung Kecil, (Charadrius alexandrinus) mencari makan sendiri atau dalam kelompok kecil dansering berbaur dengan perancah lain (MacKinnon et al., 2010).

Famili Charadriidae merupakan salah satu famili burung pantai (Shorebird). Cerek tilil (Charadrius alexandrinus) yang merupakan burung migran hanya ditemukan sebanyak $0,15 \%$ dengan aktifitas mencari makan danbergabung bersama kelompok cerek kernyut. Pada umumnya cerek tilil. Berbeda dengan cerek tilil, cerek kernyut (Pluvialis fulva) memilikiukuran tubuh lebih besar dan terdapat motif pada bulu sayapnya. Cerek kernyut ditemukan sebanyak $10,02 \%$. Cerek kernyut ditemukan sedang mencari makan sebanyak 3 kali yaitu sedang menyendiri dan sedang berkoloni sebanyak 40 ekor dan bersamaan dengan cerek tilil. Menurut MacKinnon et al., (2010), cerek kernyut memi-liki kebiasaan mencari makan sendirian atau dalamkelompok, di gosong lumpur, gosong pasir, padang rumput terbuka, lapangan, lapangan golf, atau lapangan terbang dekat pantai. Gambar 6. Cerek kernyut (atas) dan Trinil ekor kelabu (bawah) (Sumber: Doku-mentasi pribadi). Salah satu famili Sco-lopacidae yang ditemukan yaitu trinil pantai (Actitishypoleucos) termasuk kedalam famili burung pantai (Shorebirds). Trinil pantai ditemukan sebanyak 0,30\%. Trinil pantai yang ditemukan melakukan aktifitas berjemur dan mencari makan sambil menghentakkan kakinya berulang-ulang. Kebiasaan dari bu-rung migran ini yaitu sering mengunjungi habitat yang sangatluas, dari gosong lumpur pantai dan beting pasir sampai ke sawah di dataran tinggi (sampai ketinggian $1.500 \mathrm{~m}$ ), sepanjang aliran, dan pinggir sungai. Berjalan dengan cara menyentak tanpa berhenti. Terbang dengan pola yang khas, melayang dengan sayap yang kaku (MacKinnon et al., 2010).

Famili Scolopacidae lainnya yang ditemukan adalah trinil ekor kelabu (Heteroscelus brevipes). Berbeda dengan trinil pantai, trinil ekor kelabu memiliki ukuran tubuh yang lebih besar. Trinil ekor kelabu ditemukan sebanyak 1 individu digosong pantai bersamaan dengan 1 individu cerek kernyut. Menurut MacKinnon et al., (2010), trinil ekor kelabu merupakan pengunjung yang tidak umum sampai jarang ke pesisir di Sunda Besar dan di Pulau Jawa lebih banyak ditemukan di pesisir selatan. Burung ini memiliki cara berlari yang khas, yaitu mengendap-endap dengan ekor agak tinggi. Trinil ekor kelabu pada umumnya lebih menyukai beraktifitas di pantai berbatu daripada gosong lumpur, beting koral, dan pantai berpasir atau berkerikil (MacKinnon et al., 2010). Namun pada pengamatan kali ini ditemukan di gosong lumpur yang diduga bahwa burung ini sedang melakukan aktifitas mencari makan dan berjemur di bawah terik matahari pada sore hari pukul 15.33 WIB. Waktu tersebut merupakan waktu surut air laut sehingga lebih mudah bagi burung tersebut mencari makan. Famili Scolopacidae lainnya yang ditemukan yaitu gajahan pengala (Numenius phaeopus) dengan jumlah individu sebanyak $0,15 \%$. Gajahan pengala ditemukan di pantai berbatu bersama dengan cerek kernyut. Gajahan pengala merupakan burung pantai yang suka melakukan kebiasaan melakukan aktifitas di gosong lumpur, muara pasang surut, daerah berumput dekat pantai, payau, dan pantai berbatu. Biasanya hidup dalam kelompok kecil sampai besar, dan sering berbaur dengan burung perancah lain (MacKinnon et al., 2010).

Jenis burung dari famili Cuculidae yang tergolong burung migran yaitu kangkok besar (Cuculus sparverioides). Kangkok besar dijumpai sebanyak 0,61\%. Kangkok besar (Cuculus sparverioides) menetap di Hima- 
laya, Cinaselatan, Filipina, Kalimantan, dan Sumatera, sehingga dapat dikatakan bahwa kangkok besar ini sedang bermigrasi dari daerah asalnya ke Pulau Tidung Kecil. Pada musim dingin kangkok besar juga mengunjungi Sulawesi, Jawa barat, dan Bali (MacKinnon et al., 2010). Burung migran terakhir yang ditemukan adalah Layang-layang api (Hirundo rustica) sebanyak 1,82\%. Burung ini termasuk kosmopolitan ditemukan di seluruh dunia. Dibandingkan dengan marga layang-layang lainnya, layang layang api merupakan jenis yang paling luas penyebarannya (Pramanayuda, 2013). Oleh sebab itu sangat mungkin burung ini juga terlihat di Kepulauan Seribu termasuk di Pulau Tidung Kecil. Sub jenis yang ditemukan di Indonesia adalah $H$. rustica gutturalis yang pada musim dingin berbiak di Jepang, Korea dan Himalaya bagian tengah.

Terdapat 17 jenis burung yang memanfaatkan 17 jenis tegakan pohon yang ada di Pulau Tidung Kecil. Jenis burung yang memanfaatkan tegakan tersebut antara lain burung madu kelapa, tekukur biasa, remetuk laut, merbah cerukcuk, cucak kutilang, bondol peking, gagak hutan, kekep babi, bondolhaji, kipasan belang, cekakak sungai, kangkok besar, burung madu sriganti, kancilan bakau, kokokan laut, bubut pacar jambul dan burung gereja erasia.

Tiga jenis tegakan pohon yang paling sering dimanfaatkan di Pulau Tidung Kecil yaitu cemara laut (Casuarina equisetifolia), ketapang (Terminaliacatappa), dan petai cina (Leucaena leucocephala). Cemara laut ( $\mathrm{Ca}$ suarinaequisetifolia) merupakan jenis pohon yang paling sering dimanfaatkan oleh burung yaitu sebanyak $76,47 \%$ untuk berbagai aktifitas (Gambar 9). Selain itu pohon ketapang (Terminalia catappa) dan petai cina (Leucaena leucocephala) merupakan tegakan yang banyak dimanfaatkan oleh burung yang ada di Pulau Tidung Kecil dengan persentase sebanyak $41,18 \%$. Cemara laut memiliki struktur pohon yang ideal bagi kebutuhan burungburungdi Pulau Tidung Kecil. Cemara laut memiliki ukuran pohon yang tinggi sehingga memudahkan burung pemakan serangga sambil terbang melayang (aerial feeding) untuk mendapatkan pakannya. Cemara laut juga memiliki tajukyang lebar dan kokoh sehingga beberapa burung memanfaatkannya untuk beristirahat. Struktur daun yang dimiliki cemara laut berbentuk jarum sehingga jarak pandang dan pergerakan burung tidak terbatas. Oleh karena itu cemara laut paling sering dimanfaatkan oleh jenis burung di Pulau Tidung Kecil. Pohon ketapang (Terminalia cattapa) memiliki tajuk yang rindang dengancabang yang mendatar dan bertingkat. Tajuk yang lebar dan rapat serta daun yang besar dimanfaatkan burung untuk beristirahat. Struktur daun yang besar dan tajuk yang rapat membatasi pandangan bagi beberapa jenis burung yang mencari mangsa. Oleh karena itu hanya burungburung tertentu saja yang memanfaatkan pohon tersebut. Jenis-jenis burung yang memanfaatkan pohon ketapang adalah burung madu kelapa, tekukur biasa, cucak kutilang, gagak hutan, kekep babi dan cekakak sungai. Pohon petai cina merupakan tegakan yang dimanfaatkan oleh beberapa jenis burung, seperti remetuk laut, merbah cerukcuk, cucak kutilang, bondol peking, bondol haji, cekakak sungai dan kokokan laut. Hal ini dikarenakan tumbuhan ini memiliki biji di dalam polong yang dijadikan sumber pakan bagi burungburung pemakan biji, serta batang yang kuat dan elastik yang disukai berbagai jenis burung untuk bertengger. Keberadaan tegakantegakan tersebut berperan penting bagi keberadaan burung. Oleh sebab itu, tegakantegakan pohon tersebut harus dipertahankan keberadaannya agar burung-burung yang memanfaatkannya tetap ada dan lestari. Vegetasi di Pulau Tidung Kecil dimanfaatkan oleh burung untuk melakukan aktifitas.

Vegetasi di Pulau tidung kecil sebagian besar dimanfaatkan oleh burung untuk terbang dan bertengger. Sebanyak 44,26\% melakukan aktifitas terbang dansebanyak 43,03\% melakukan aktifitas istirahat (resting). Hal ini disebabkan terdapat beberapa jenis burung yang mengganggu maupun terganggu karena persaingan dalam mendapatkan sumberdaya, sehingga banyak burung yang terbang dan berpindah untuk bertengger di pohon lain. Selain itu habitat di Pulau 
Tidung Kecil cocok untuk tempat beristirahat bagi burung karena terdapat beberapa tegakan khas pantai yang kuat dan memiliki tajuk yang lebar.

Adapun aktifitas lain yang dilakukan oleh burung-burung yang ada di Pulau Tidung Kecil yaitu sebanyak 9,84\% mencari makan (feeding) dan bersuara, sebanyak 3,69\% melakukan aktifitas sosial (social) yang meliputi prilaku berkompetisi, interaksi antara induk dan anaknya, serta hubungan seksual, serta sebanyak $1,23 \%$ melakukan aktifitas bersarang (nesting). Hal ini disebabkan Pulau Tidung Kecil memiliki luasan yang relatif kecil dibandingkan pulau-pulaulain di kepulauan seribu sehingga rentan terhadap gangguan.

Ketersedian bahan-bahan pembuatan sarang yang terbatas bagi burung tertentu juga merupakan penyebab akifitas bersarang sedikit. Diduga burung-burung memilih pulau lain sebagai tempat bersarang, sehingga hanya sebagian kecil burung yang bersarang di pulau ini seperti bondol peking (Lonchura punc-tulata ), teramati bersarang di pohon kedon-dong kambing (Spondias sp) dan pandan laut (Pandanus tectorius). Rendahnya nilai aktifitas bersuara dipengaruhi oleh komposisi jenisburung. Ekosistem Pulau tidung kecil hanya dapat mendukung kehidupan beberapa jenis burung pengicau di pulau tersebut. Selebihnya, berung-burung di Pulau Tidung Kecil dihuni oleh kelompok burung air dan burung pantai yang cenderung lebih jarang bersuara.

Berdasarkan komposisi jenis burung yang ada di Pulau Tidung Kecil, status perlindungan jenis burung dikelompokan kedalam 3 acuan, yaitu IUCN Red Data Book, PP No.7 tahun 1999 dan CITES. Status perlindungan jenis burungberdasarkan IUCN di Pulau Tidung Kecil 100\% masuk kedalam kriteia Leastconcern atau beresiko rendah. Selain itu, terdapat 7 jenis burung yang dilindungi oleh Undang-Undang yaitu berdasarkan PP No.7 tahun 1999. Namun tidak terdapat jenis burung yang dilindungi oleh CITES di Pulau Tidung Kecil.

Perlindungan burung berdasarkan IUCN Red Data Book merupakan perlindungan jenis burung yang berupa status keterancaman. Hasil dari penelitianini menunjukkan bahwa status keterancaman jenis burung yang terdapat di Pulau Tidung Kecil yaitu 100\% masuk kedalam kriteria Least Concern. Jenis burungyang terdapat di pulau tidung kecil secara IUCN Red Data Book seluruhnya masuk kedalam kriteria Least concern yang artinya memiliki resiko yang rendah terhadap kepunahan secara global. Namun demikian burung di Pulau Tidung kecil tetap berpotensi mengalami kepunahan secara lokal.Seperti yang telah dibahas sebelumnya, keberadaan burung di pulau tidung kecil berpotensi mengalami gangguan habitat oleh manusia yang dapat menurunkan jumlah individu dan mengancam populasinya. Hal tersebut sesuai pernyataan Sukmantoro et al., (2007) bahwa keterancaman burung di suatu lokasi dikarenakan mempunyai populasi yang kecil dan terdapat penurunan yang tajampada jumlah individu di alam.

Jenis burung yang masuk ke dalam status perlindungan berdasarkan PPNo.7 tahun 1999 yaitu terdapat 7 jenis yang merupakan jenis dari famili Ardeidae, Nectarinidae, Alcediniidae, Rhipiduridae dan Scolopacidae. Hal ini menunjukkan bahwa Pulau Tidung merupakan ekosistem penting yang harus dilindungi agar keberadaan burung tersebut dapat dipertahankan. Pemerintah Republik Indonesia menyusun PP No. 7 tahun 1999 tentangkonservasi sumber daya alam hayati dan ekosistemnya mengatur status perlindungan flora dan fauna di Indonesia. Tujuh jenis yang termasuk jenis burung wajib ditetapkan sebagai satwa yang dilindungi karena berdasarkan catatan pemerintah termasuk ke dalam salah satu kriteria satwa dilindungi seperti mengalami penurunan populasi, ukuran populasinya yang kecil, dan memiliki sebaran yang terbatas atau endemik. Jenis burung dari famili Ardeidae yang dilindungi dan ditemukan di Pulau Tidung Kecil adalah Ardea cinerea (cangak abu) dan Egretta sacra (kuntul karang). Burung tersebut dilindungi karena penyebarannya terbatas dan hanya ditempat-tempat tertentu. Penyebaran global cangak abu yaitu di Afrika, Erasia, sampai Filipina dan Sunda, sedangkan 
penyebaran global kuntul karang dikawasan pesisir Asia timur, Pasifik barat, dan Indonesia sampai Pulau Irian, Australia, dan Selandia Baru. Penyebaran lokal cangak abu umumnya tersebar didekat laut, tetapi kadangkadang ditemukan juga di danau-danau di pedalaman sampai ketinggian $900 \mathrm{~m}$ sedangkan di Kalimantan diduga hanya sebagai pengunjung, sedangkan penyebaran lokal kuntul karang hanya terdapat di terdapatdi seluruh Sunda Besar (Mackinnon et al., 2010).

\section{KESIMPULAN}

1. Keanekaragaman jenis burung di Pulau Tidung Kecil, Kepulauan Seribu, Jakarta masuk ke dalam kategori sedang, kemerataan tinggi dan kekayaan jenis burung masuk ke dalam kategori baik.

2. Tegakan pohon yang paling banyak dimanfaatkan oleh burung di Pulau Tidung Kecil adalah Cemara laut (Casuarina equisetifolia), strata vertikal vegetasi pohon yang paling banyak dimanfaatkan oleh burung.

\section{SARAN}

Untuk menjaga keberadaan jenis-jenis burung yang ada di Pulau Tidung Kecil maka perlu dijaga ketersediaan habitat dan tegakan pohon serta perludilakukan pengamatan secara berkala.

\section{DAFTAR PUSTAKA}

Andam, D. (2012). Pulau Tidung Bermasalah? Ini Solusinya. internet. (26 November 2014, pukul 14.15 WIB). Diakses dari www.republika.co.id.

Bibby, C. J., Burges, N.D., \& Hill, D. A. (2000). Birdcencus techniques. Academic Press. London.

Hernowo, J. B., \& Prasetyo, L. B. (1989). Konsep ruang terbuka hijau di kota sebagai pendukung pelestarian burung. Media Konservasi. 2 (4), 61-71.

Howes, J., Bakewell, D., \& Noor, Y. R. (2003). Panduan Studi Burung Pantai.Wetlands International Indonesia Programme. Bogor.
Idaman, D. W. (2007). Komunitas burung terrestrial di Suaka Margasatwa Pulau Rambut. Skripsi. Fakultas Kehutanan IPB. Bogor.

Van-Helvoort, B. (1981). A Study of Bird Population in The Rural Ecosystem of West Java, Indonesia a Semi Quantitative Approach. Nature Conservation Dept. Agriculture University Wageningan. Wageningen The Netherland.

Kaban, A. (2013). Keanekaragaman Jenis Burung pada Beberapa Tipe Tegakan di Hutan Pendidikan Gunung Walat, Sukabumi, Jawa Barat. Skripsi. Fakultas Kehutanan IPB. Bogor.

Kapisa, H. A. (2011). Keanekaragaman jenis Burung Pada Areal HutaKonsesi PT Manokwari Mandiri Lestari (MML) Kabupaten Teluk Bintuni. Skripsi.U niversitas Negeri Papua. Manokwari.

Krebs, C. J. (2013). Ecological Methodology. Harper \& Row Publisher. New York.

Krebs, J. R., \& Davies, N. B. (1993). An Introduction to Behavioural Ecology. Blackwell Scientific Publications, London.

Kurnia, I., Fadly, H., Kusdinar, U., Gunawan, W. G., Idaman, D. W., Dewi, R. S., Yandhi, D., Saragih, G. S., Ramdhan, G. F., Djuanda, T. D., Risnawati, R., \& Firdaus, M. (2005). Keanekaragaman Jenis Burung di Taman Nasional Betung.

Ludwig, J. A., \& Reynolds, J. F. (1988). Statistical Ecology : A Primer in Methods and Computing. John Wiley \& Sons, New York.

MacKinnon, J. (1990). Burung-burung di Jawa-Bali. LIPI-Birdlife International Indo-nesia Programme. Bogor.

Mackinnon, J., PhillipsKand, B., \& VanBalen, B. (2010). Burung-burung di Sumatera, Jawa, Bali, dan Kalimantan. Puslitbang Biologi-LIPI/BirdLife Indonesia.

Magguran, A. E. (1988). Ecological Diversity and its Measurment. Pricenton University Press. New Jersey.

Mardiastuti, A. (1992). Habitat and Nest-site Characteristics of Waterbirds Indonesia 
Pulau Rambut Nature Reserve, Jakarta Bay, Indonesia. Ph.D. Dissertation, Michigan State University.

Mulyani, Y. M., \& Pakpahan, A.M. (1993). Studi Pendahuluan Tentang

Keanekaragaman Burung di Kota Baru Bandar Kemayoran, Jakarta. Media konservasi. 4 (2), 59-63.

Odum, E. P. (1993). Dasar-dasar Ekologi. Edisi Ketiga. Yogyakarta: Universitas Gajah Mada.

Pramanayuda, I. (2013). Dari Manakah Layang-layang Api Berasal?. (13 juni 2015). Diakses dari www.blogs. uajy.ac.id

Santosa, Y. (1995). Teknik Pengukuran Keanekaragaman Satwaliar. Jurusan Konservasi Sumberdaya Hutan Fakultas
Kehutanan-Institut Pertanian Bogor, Bogor. Tidak dipublikasikan.

Sukmantoro, W., Irham, M., Novarino, W., Hasadungan, F., Kemp N., \& Muchtar M. (2007). Daftar Burung Indonesia No.2. Indonesian Ornithologists Union. Bogor.

Swastikaningrum, H., Hariyanto, S., \& Irawan, B. 2012. Keanekaragaman jenis burung pada berbagai tipe pemanfaatan lahan di kawasan muara kali lamong, perbatasan surabaya Gresik. Berk. Penel. Hayati. 17, 131-138.

Utari, W. D. (2000). Keanekaragaman Jenis Burung Pada Beberapa Tipe Habitat Di Areal Hutan Taman Industri Pt. Riau Adalat Pulp Dan Paper Dan perkebunan Sawit Pt. Duta Palma Nusantara Grup. IPB. Bogor. 